\title{
Coping with being cooped up: Social distancing during COVID-19 among 60+ in the United States
}

\author{
Kerstin Gerst Emerson ${ }^{1}$
}

Suggested citation Emerson, KG. Coping with being cooped up: Social distancing during COVID-19 among 60+ in the United States. Rev Panam Salud Publica. 2020;44:e81. https://doi.org/10.26633/RPSP.2020.81

ABSTRACT Objectives. This study examined the impact of sheltering in place and social distancing among adults aged 60 and older during the 2020 outbreak of COVID-19 in the United States.

Methods. Using convenience sampling respondents were asked to complete a web-administered survey to explore impact of social distancing on loneliness, stress, and behavioral changes. The analytic sample consisted of 833 responses of persons aged 60 and older.

Results. A large portion reported being stressed (36\%), and/or being lonely (42.5\%). Nearly $1 / 3$ stated that their sense of loneliness increased during the time of social distancing. Respondents reported engaging in more solitary activity (and fewer in-person activities), using email and text messages more than usual, and spending more time on computers/tablet than usual. Approximately $2 / 3$ reported using more social media than usual. These differed significantly by younger (age 60-70) and older (71+) respondents. Additionally, changes in physical activity, drinking, recreational drug use and sleeping pattern changes differed by age.

Conclusions. Social distancing has significant consequences on loneliness and health behaviors among adults in the United States, many of which differ by age group. Results have implications for continued shelter in place practices, but also for any older adult that may be homebound for other reasons.

Keywords $\quad$ Aging; coronavirus infections; United States.

The worldwide spread of COVID-19 has created a pandemic unlike any seen in a century, and it is disproportionately affecting older adults (1). Global data, including those from the United States, consistently show higher death rates among older adults and those with underlying conditions (2). To curb disease transmission and risk of infection, the US began recommending restrictions of social interactions for these most vulnerable populations. Specifically, on March 5, 2020, the Centers for Disease Control (CDC) warned that older adults were particularly vulnerable to the COVID-19 and encouraged older adults to take extra precautions (2). Recommended precautions included social distancing and sheltering in place. Social distancing is a public health practice to reduce disease transmission by preventing people with an illness from coming into close contact with non-infected people (3). Similarly, sheltering in place is aimed at reducing transmission rates by remaining at home except for essential travel. Adhering to these recommendations means many older adults in the US have been at home with minimal outside contact for an extended period of time.

Little is known about how this extended period of sheltering in place has impacted older adults. However, researchers are concerned that current public health safety measures pose a risk of loneliness, even among those that are living with other family members (1). Social interaction is integral to human well-being, and the impact of not having ones social needs met (aka loneliness) can be wide ranging. Loneliness has been connected to both morbidity and mortality $(4,5)$. Loneliness can be a particularly important concern for older adults, who may have additional risk factors, such as physical and cognitive impairment, death of loved ones, and decreases in economic

\footnotetext{
1 University of Georgia, Athens, United States of America $\square$ Kerstin Emerson, emerson@uga.edu
} 
resources $(6,7)$. Sheltering in place and social distancing may be adding additional risk factors for loneliness as older adults lose many potential outlets for social interaction, such as going to religious services, seeing friends and family, shopping, and group exercise classes.

While data on the impact of social distancing for COVID19 is not yet available, research on prior quarantining events suggests that one unintended consequence of such measures is psychological distress. Most recently, research on the impact of mandated quarantine during the severe acute respiratory syndrome (SARS) outbreak in Canada showed a high level of psychological distress among respondents (8).

The purpose of this study was to explore how adults aged 60 and older in the US are coping with social distancing and sheltering in place during the COVID-19 pandemic.

Specifically, the survey hoped to answer two main questions: 1) What have been the effects of social distancing on adults aged 60 and older, and 2) What have been behavioral and social communication changes since social distancing started? The answers can shed light on challenges experienced by those social distancing, and can guide potential public health interventions strategies.

\section{MATERIALS AND METHODS}

Survey Instrument. We conducted a web-based survey in Qualtrics, which consisted of 28 questions. A web-based format was chosen due to budget and time constraints; it was important to reach those practicing social distancing during the event to avoid recall bias (8). The survey was open for two weeks, beginning on March $30^{\text {th }}$ and concluding on April $12^{\text {th }}, 2020$. The sampling of the survey was a convenience sample, with links sent out on social media and gerontology listservs. Only persons aged 60 and older were asked to respond. Each respondent was asked to forward the survey on to other persons aged 60 and older. The study was approved by the University of Georgia Institutional Review Board (IRB\# 00002133).

Analytic sample. 922 persons initiated the survey, but only 843 (91.4\%) completed the survey. An additional 10 responses were not included in the analytic sample because they did not provide their age or because they were not in the United States. The final sample size was 833 respondents living in the US, aged 60 and older.

Variables. The survey collected socio-demographic data, including age (top-coded at 85), sex (male, female, other), race (White, Black/African American, American Indian/Alaska Native, Asian, Native Hawaiian/Pacific Islander, Other), ethnicity (Hispanic or Latino as defined by the US Census (14)), employment status (part-time, full-time, not employed), and household size (continuous). Additionally, respondents were asked to estimate how many people they continue to be in contact with in person, but outside of the home (no one else, 1, 2-3, 4 or more). Respondents were also asked about the type of home they live in (apartment, house, nursing home, assisted living, other).

Loneliness was determined by asking respondents: "Since you started socially distancing, have you felt lonely?" (yes, most of the day/yes, some of the day/no, never). For analyses all respondents who answered most or some were coded as lonely. Respondents were then asked a follow up loneliness question: "Do you feel more, less, or the same level of loneliness compared to the time before you were socially distancing?".

Stress was measured by self-report response to the prompt: "Stress means a situation in which a person feels tense, restless, nervous or anxious or is unable to sleep at night because their mind is troubled all the time. Do you feel this kind of stress these days?" (answer choices were a 5-point Likert scale). For analyses the five answer choices were collapsed into three groups ( 1 =a great deal/a lot, $2=$ moderate amount, 3- A little/not at all). Relationships was determined by the question: "Do you feel like you have close relationships that bring you emotional security and well-being?" (answer choices were yes, definitely/yes, somewhat/no, not at all). Self-rated health was measured by a 5-point Likert scale ranging from poor to excellent.

Finally, respondents were asked to choose all that apply from a range of behavioral and communication changes since beginning social distancing. These included doing more or less: sleeping, engaging in physical activity, smoking, drinking alcohol, using recreational drugs, eating, solitary activities, engaging in in-person activities, making/receiving phone calls, using social media, emailing, ending/receiving text messages, and spending time on the computer/tablet/phone.

Analyses. Data are presented in descriptive format. Means were calculated to summarize continuous variables. For categorical variables, group proportions were calculated. To explore differences by age, the results were divided into younger (ages 60-70) and older (ages 71+). Because sample cell sizes were small, all statistical comparisons by age are conducted using Fisher's Exact test. Stress, loneliness, and relationship responses were examined by whether respondents lived alone, using Pearson chi-square tests. A p-value of $<0.05$ was considered to be significant for all analyses. All analyses were conducted using SPSS v21.

\section{RESULTS}

Description of the sample. The sample age range was 60 to $85+$ (top-coded), with $62.8 \%$ in the younger (aged 60-70) category (Table 1$)$. A majority $(80.5 \%)$ of the sample was female, White (96\%), and not Hispanic (97.9\%). Race/ethnicity did not differ by age of respondents, though the younger age group was significantly more likely to be female $(84.3 \%)$ compared to the older age group (74.1\%).

Who is social distancing and what does their household look like? The average number of days spent practicing social distancing for this sample was 16.95 (range 2-65 days, SD 5.8). This did not differ significantly by age. For context, the survey opened 25 days after the official CDC recommendations were published for older adults and ended 39 days after the recommendations.

About $85 \%$ of survey respondents lived in a house, $8.6 \%$ lived in an apartment, and 5.7\% lived in other locations, such as condos, or townhomes. A majority of respondents were living either with one other person $(64.3 \%)$ or living alone $(21.3 \%)$.

Approximately two-thirds $(67.7 \%)$ of respondents were not employed, although this differed significantly by age. The older age group had higher rates $(86.7 \%)$ or not working, compared to $56.5 \%$ of younger age group. Of those that were employed, $28-30 \%$ usually work from home and continue to work from home (across both age groups). Among the older respondents $48.6 \%$ usually worked outside the home, but were now working 
Table 1. Description of the sample, by age category $(n=833)$

\begin{tabular}{|c|c|c|c|c|}
\hline & Total Sample & $\begin{array}{l}\text { Aged } 60-70 \text { yes } \\
\quad(n=523)\end{array}$ & $\begin{array}{l}\text { Aged } 71+\text { yes } \\
(n=310)\end{array}$ & $p$-value \\
\hline \multicolumn{5}{|l|}{ Demographics } \\
\hline \multicolumn{5}{|l|}{ Race } \\
\hline White & 96.0 & 94.8 & 98.0 & 0.082 \\
\hline Black or African American & 1.9 & 2.9 & 0.3 & \\
\hline American Indian or Alaska Native & 0.2 & 0.2 & 0.3 & \\
\hline Asian & 0.2 & 0.4 & 0.0 & \\
\hline Other & 1.6 & 1.7 & 1.3 & \\
\hline Hispanic (yes) & 2.1 & 2.2 & 2.1 & 0.563 \\
\hline Female & 80.5 & 84.3 & 74.1 & 0.000 \\
\hline $\begin{array}{l}\text { Days since respondent began social distancing } \\
\text { (mean, social distancing) }\end{array}$ & $16.95(5.8)$ & $16.69(5.4)$ & $17.38(6.2)$ & 0.101 \\
\hline \multicolumn{5}{|l|}{ Employment Status } \\
\hline Not employed & 67.7 & 56.5 & 86.7 & 0.000 \\
\hline Usually work from home, continue to work from home & 30.3 & 30.5 & 28.6 & \\
\hline Usually work outside the home, now working at home & 59.7 & 61.6 & 48.6 & \\
\hline $\begin{array}{l}\text { Currently work outside the home and continue to work outside } \\
\text { the home }\end{array}$ & 4.6 & 3.9 & 8.6 & \\
\hline \multicolumn{5}{|l|}{ Household } \\
\hline Household size & & & & 0.026 \\
\hline Living alone & 21.3 & 19.0 & 25.3 & 0.083 \\
\hline Living with one other person & 64.3 & 65.4 & 62.5 & \\
\hline Living with two or more people & 14.4 & 15.6 & 12.3 & \\
\hline Type of home & & & & 0.132 \\
\hline House & 85.6 & 87.5 & 82.6 & \\
\hline Apartment & 8.6 & 7.9 & 9.7 & \\
\hline Other (e.g. Townhome, condo) & 5.7 & 4.4 & 7.7 & \\
\hline \multicolumn{5}{|l|}{ Social contact outside the home } \\
\hline $\begin{array}{l}\text { How many people outside of household do you see regularly in } \\
\text { person? }\end{array}$ & & & & 0.334 \\
\hline No one else & 51.2 & 48.7 & 5.3 & \\
\hline 1 person & 15.3 & 16.0 & 14.2 & \\
\hline 2-3 people & 21.9 & 23.1 & 19.7 & \\
\hline 4+ people & 11.6 & 12.1 & 10.7 & \\
\hline Phone contact & & & & 0.246 \\
\hline Never & 5.5 & 5.7 & 5.2 & \\
\hline Once a day & 37.5 & 36.4 & 39.5 & \\
\hline 2-3 times a day & 38.6 & 37.5 & 40.5 & \\
\hline $4+$ day & 18.3 & 20.3 & 14.9 & \\
\hline Video Call contact & & & & 0.000 \\
\hline Never & 43.6 & 37.6 & 53.8 & \\
\hline Once a day & 43.9 & 46.7 & 39.1 & \\
\hline 2-3 times a day & 10.4 & 12.8 & 6.4 & \\
\hline $4+$ day & 2.1 & 2.9 & 0.7 & \\
\hline Do you feel like you have close relationships? & & & & 0.156 \\
\hline Yes, definitely & 84.6 & 82.8 & 87.7 & \\
\hline Yes, somewhat & 14.2 & 15.9 & 11.3 & \\
\hline \multicolumn{5}{|l|}{ Mental Health } \\
\hline Self-rated health & & & & 0.449 \\
\hline Excellent & 24.3 & 22.2 & 27.1 & \\
\hline
\end{tabular}


Table 1. Description of the sample, by age category $(n=833)$ (continued)

\begin{tabular}{lccc} 
& Total Sample & $\begin{array}{c}\text { Aged } 60-70 \text { yes } \\
(n=523)\end{array}$ & $\begin{array}{c}\text { Aged } 71+\text { yes } \\
(n=310)\end{array}$ \\
Very Good & & 45.0 & 43.2 \\
Good & 44.4 & 27.0 & 23.5 \\
Fair & 25.7 & 4.8 & 4.5 \\
Poor & 4.7 & 1.0 & 1.6 \\
Since social distancing do you feel lonely (yes, all or yes, some) & 1.2 & 42.5 & 27.5 \\
Compare to loneliness before social distancing & 42.9 & 33.1 & 3.6 \\
More lonely & & 3.5 & 69.4 \\
Less lonely & 30.9 & 63.4 & 0.184 \\
About the same & 3.5 & & 74.2 \\
Feel stressed & 65.6 & 56.5 & 19.4 \\
A little/not at all & & 27.6 & 6.5 \\
A moderate amount & 63.1 & 15.9 & 0.000 \\
A lot/great deal & 24.5 & & \\
\hline Note: totals may not sum to 100\% due to rounding & 12.4 & &
\end{tabular}

Note: totals may not sum to $100 \%$ due to rounding

from home because of COVID-19, compared to $61.6 \%$ of the younger group.

What social contacts do people have? More than half (51.2\%) of respondents saw no one else outside their household, 15.3\% saw only one person, $21.9 \%$ saw $2-3$ people, and $11.6 \%$ saw four or more people. Most (94.5\%) respondents spoke with someone on the phone at least once a day, and $56.4 \%$ spoke to someone using video calling (e.g. Facetime/skype) at least once a day. Video calls were significantly more common among the younger respondents, with nearly $53.8 \%$ of older respondents saying the never used video calls, compared to $37.6 \%$ of younger respondents. Nearly all respondents $(98.8 \%)$ reported having at least some close relationships that bring them emotional security and well-being.

How are people feeling? Respondents rated their health fairly highly, with $94.4 \%$ rating their health as good, very good, or excellent. Approximately $43 \%$ of respondents reported feeling lonely some or most days. For about two-thirds (65.6\%) of the respondents their level of loneliness had not changed, though $30.9 \%$ stated that they are more lonely now compared to before they were socially distancing. About $3.5 \%$ felt less lonely.

Over one-third (36.9\%) of the sample reported being moderately to a great deal stressed. This differed significantly by age. Older respondents reported higher rates of being only a little or not at all stressed out (74.2\%) compared to younger respondents (56.5\%).

Analyses stratified by living alone. Some health measured differed significantly by whether or not respondents lived alone (Table 2). Those living alone had much higher rates of current loneliness $(59.3 \%)$ compared to those that lived with others $(38.4 \%)$. Those living alone were also significantly more likely to report that their loneliness had increased since social distancing $(42.4 \%)$ compared those living with others $(27.9 \%)$. Those living alone were less likely to report having a close relationship that brings them emotional security and well-being, where $3.6 \%$ said they didn't have this at all, and $20.4 \%$ said they had it somewhat. This was compared to $0.0 \%$ for not at all and $12.7 \%$ for somewhat among those living with others. Stress, having close relationships, and physical health did not differ significantly by living alone.
Table 2. Physical and mental health by living alone status

\begin{tabular}{lccc} 
& $\begin{array}{c}\text { Live alone } \\
(n=167)\end{array}$ & $\begin{array}{c}\text { Live with } \\
\text { others } \\
(n=623)\end{array}$ & p-value \\
$\begin{array}{l}\text { Since social distancing do you feel } \\
\text { lonely (yes, all or yes, some) }\end{array}$ & 59.3 & 38.4 & 0.000 \\
$\begin{array}{l}\text { Since social distancing how does } \\
\text { loneliness now compare to before? }\end{array}$ & & & \\
$\quad$ More lonely & 42.4 & 27.9 & 0.000 \\
$\quad$ Less lonely & 0.0 & 4.1 & \\
$\quad$ About the same & 57.6 & 68.1 & \\
& & & \\
Do you feel like you have close & & & \\
relationships? & & & \\
$\quad$ Yes, definitely & 76.0 & 86.7 & 0.000 \\
$\quad$ Yes, somewhat & 20.4 & 12.7 & \\
$\quad$ No Not at all & 3.6 & 0.6 & \\
\hline
\end{tabular}

Changes in behaviors are presented below and in Table 3.

Health Behaviors. Sleep patterns were impacted for a little over $1 / 3$ of the sample, with $27.1 \%$ reporting more sleep than usual, and $15.8 \%$ reporting less sleep. Younger respondents were significantly more likely to report sleeping less. Physical activity levels changed as well, in both directions. About one-quarter $(24.6 \%)$ of respondents engaged in more physical activity, while $37.3 \%$ engaged in less physical activity than usual. Younger respondents were significantly more likely to increase their physical activity, whereas older respondents were significantly more likely to decrease their physical activity.

Alcohol intake increased for $12.2 \%$ of the sample, but decreased for $4.4 \%$ of the sample. Increase in alcohol consumption was significantly higher for the younger age group $(14.9 \%)$ compared to younger respondents $(7.7 \%)$. Smoking and recreational drug use both had smaller changes, with $1.3 \%$ smoking more than usual and $1.1 \%$ smoking less than usual, and $1.4 \%$ taking more recreational drugs and $1.0 \%$ taking fewer drugs. Less use of recreational drugs than usual was significantly more common among older adults, though sample sizes are small. 
Table 3. Changes in behavior since COVID-19

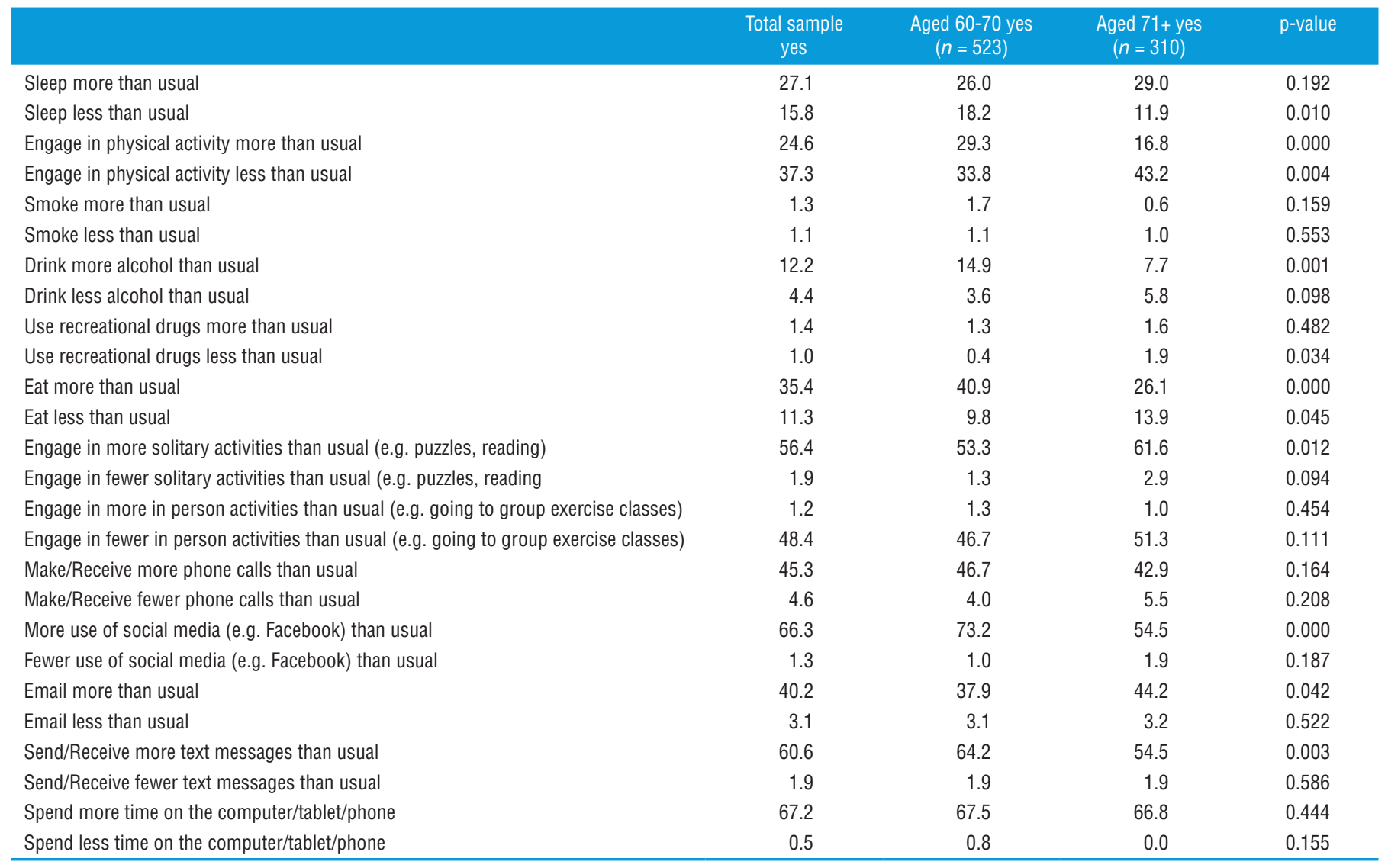

Note: Respondents were asked to choose all that apply

Since social distancing, over one-third (35.4\%) of respondents report eating more than usual, and $11.1 \%$ ate less than usual. This differed significantly by age, where younger people were more likely to report eating more, and older respondents were more likely to report eating less.

A majority of respondents (56.4\%) engaged in more solitary activities, and $1.2 \%$ engaged in fewer of those activities. A larger proportion of older respondents reported engaging in solitary activities (61.6\%) compared to younger respondents $(53.3 \%)$. While some $(1.1 \%)$ have engaged in more in-person activities than usual, more $(48.4 \%)$ report less in person activities.

Communication. Among respondents, 4.6\% make/receive fewer phone call, $1.3 \%$ use social media less, 3.1\% email less, $1.9 \%$ send/receive fewer text messages, and $0.5 \%$ spend less time on their computer/tablets / or phones. However, for a much larger group of respondents, each of these styles of communication increased. Among respondents, 45.3\% make/receive more phone calls, $66.3 \%$ use social media more, $40.2 \%$ email more than usual, $60.6 \%$ send / receive more text messages, and $67.2 \%$ spend more time on their computer/tablet/or phones than usual.

Several of these communication styles different significantly by age. The younger respondents were significantly more likely to increase their social media use compared to older respondents (73.2 vs. $54.5 \%$, respectively). Younger respondents also indicated an increased use of text messages (64.2\%) compared to older respondents (54.5\%) Alternatively, the older respondent group reported increased use of email (44.2\% vs. $37.9 \%$ ).

\section{DISCUSSION}

While social distancing is not a new phenomenon (13), it was never as sustained in the US or as prevalent as it has been since the COVID-19 outbreak. While the CDC provided guidance for older adults and adults with high-risk conditions, for most people the process of sheltering in place and social distancing is asking them to create a new normal with little to no precedent to lean on. One potential concern is the higher risk of loneliness as we decrease social contacts. This may be particularly concerning for older adults, who have more risk factors for loneliness. The goal of this survey was to see how people aged 60 and older are doing given the recommendations to practice social distancing.

The survey results showed that some respondents are adjusting well and not feeling lonely or stressed. However, a significant portion of adults reported experiencing at least some distress. Over a third (36\%) of respondents reported feeling moderate to a great deal of stress during this time. Those over age 70 were less likely to report stress, however. This stress and age pattern follows previous data showing decreases in stress by age (9). It is not clear from this cross-sectional data if this age pattern is a cohort effect (reflecting history and life experiences born around the same time) or a difference in individuals' circumstances.

Additionally, a large portion of respondents (43\%) noted being lonely. Loneliness rates did not differ significantly by 
age. A recent review suggests that $25-29 \%$ of Americans aged 70 years and older reporting being lonely (10), suggesting that this sample had relatively high rates. Rates of loneliness were significantly higher among those living alone (59.4\%). However, even those living with others had relatively high rates of loneliness $(41.7 \%)$. This supports previous research that simply living with others does not erase the risk of loneliness (11).

Perhaps most notable is that many respondents (31\%) stated that their sense of loneliness increased during the time of social distancing. This suggests that social distancing practices are having an impact on a portion of those aged 60 and older. Respondents who lived alone were more likely to report an increase in loneliness. This indicates that those living alone are a particularly vulnerable group to increased loneliness during periods of quarantine.

Not surprisingly, a large portion of respondents reported engaging in more solitary activity (and fewer in-person activities). Respondents also reported using email and text messages more than usual and spending more time on computers/tablet than usual. Two-thirds of respondents reported using more social media than usual.

Some of these behaviors differed significantly by age. For the older age group, adults they were more likely to engage in less physical activity, and to eat less. While participating in less physical activity is probably not a healthy behavior, it is unclear whether eating less is healthy or not. This likely depends on the individual's weight and health, as well as in the nutritional changes made with eating less. Unlike their younger counterparts (aged 60-70), older respondents were not drinking more alcohol (in fact, they were more likely to report lower alcohol intake, though this difference was only marginally significant). More older adults reported less recreational drug use (though this was a very small response rate). Younger respondents were more likely to report sleeping less.

While there is no one clear overall pattern by age, the data suggest that those in the younger age category may be engaging in less healthy behaviors during COVID-19. In this sample, younger people are more stressed, drinking more alcohol, sleeping less, and eating more. They are, however, engaging in more physical activity, which for many is assumed to be a healthy behavior.

Communication also differed by age. While both age groups reported using social media more than usual, those in the younger age group reported this much more often than those aged 70 and older (73\% vs. 55\%, respectively). The younger group also used texts more often. Those in the older age category reported more email use instead. This suggest that intervention and public health communication strategies may need to differ by age category.
These results have implications for continued shelter in place practices, but also for how to intervene with any population of older adults that may be homebound for any number of reasons (e.g. health issues, transportation). The high level of engagement with social media suggests that for all groups social media can play an important role in interventions. This is especially the case for those aged 60-70. Doing media-based interventions through platforms such as Facebook live may be an effective way to reach this population. Interventions could include social activities, live exercise activities, or social media public health messaging campaigns. On the other hand, those in the older age category were more likely to use the phone and email. It may be better to target interventions through phone or email for this population. Examples include connecting people to hotline/ warmline services such as the Institute on Aging's Friendship line, which provides free telephone support for older adults that are lonely (12)

While interventions should certainly be targeted to those living alone, it is important not to ignore those that are living with others. These data show that those living with others are still vulnerable to loneliness.

This study had some limitations. The survey was a convenience sample of a relatively small number of adults compared to the total number of adults that are actively practicing social distancing in the US. In fact, since the survey was online, a specific subset of adults were likely not reached with this survey. This includes, but is not limited to, rural elders with limited internet access. It is also possible that a self-selection effect may have occurred (8), where those who either felt the greatest or the least effects of social distancing chose to complete the survey. Therefore, the results are not generalizable and should be interpreted with caution. Additionally, the survey was fielded in the first 2-3 weeks of the social distancing, which likely only captures the immediate impact of social distancing. Future research should explore the impact of a longer duration of social distancing.

In conclusion, this survey provides a first glimpse into the lives of adults aged 60 and older living through the unprecedented public health situation caused by the COVID-19 pandemic. The results can increase awareness of potential stress, loneliness and health behavior changes for public health officials, as well as point towards the communication methods that may be most effective for interventions.

\section{Conflicts of interest. None declared.}

Disclaimer. Authors hold sole responsibility for the views expressed in the manuscript, which may not necessarily reflect the opinion or policy of the RPSP/PAJPH and/or PAHO.

\section{REFERENCES}

1. Girdhar R, Srivastava V and Sethi S. Managing mental health issues among elderly during COVID-19 pandemic. J of Geriatr Care Res. 2020; 7(1):29-32.

2. Centers for Disease Control [Internet]. People who are higher risk for severe illness. CDC Coronavirus Disease (2019) COVID-19. 2020 (cited March 5, 2020). Available from: https://www.cdc.gov/ coronavirus/2019-ncov/need-extra-precautions / people-at-higher -risk.html?
3. Pearce K. What is social distancing? Johns Hopkins University; 2020. (Cited March 13, 2020). Available from: https://hub.jhu.edu/2020 /03/13/what-is-social-distancing/.

4. Holt-Lunstad J, SmithTB, Layton, JB. Social relationships and mortality risk: a meta-analytic review. PLoS Med. 2010;7(1):e1000316.

5. Peplau LA, Perlman D. Loneliness: A Sourcebook of Current Theory, Research and Therapy. Perspectives on loneliness. New York NY:Wiley; 1985. p. 1-18. 
6. Gerst-Emerson K, Jayawardhana J. Loneliness as a public health issue: The impact of loneliness on health care utilization among older adults. 2015. Am J Public Health. 2014; 105:1013-19.

7. Dykstra PA. Older adult loneliness: myths and realities. Eur J Aging. 2009;6(2):91-100.

8. Hawryluck L, Gold WL, Robinson S, Pogorski S, Galea S, Styra R. SARS control and psychological effects of quarantine, Toronto, Canada. Emerg Infect Dis. 2004;10(7):1206-12.

9. Newport F. Gallup. Don't worry, be 80: Worry and stress decline with age; 2009. (Cited April 14, 2020). Available from: https://news .gallup.com/poll/124655/dont-worry-be-80-worry-stress-decline -age.aspx.

10. Ong AD, Uchino BN, Wethington E. Loneliness and health in older adults: A mini-review and synthesis. Gerontology. 2016;62(4):443-49.

11. Klinenberg E. Social isolation, loneliness, and living alone: Identifying the risks for public health. Am J Public Health. 2016; 106(5):786-7.
12. Institute on Aging. Friendship Line, 2020. (Cited: April 20, 2020). Available from: https://www.ioaging.org/services/all-inclusive -health-care/friendship-line.

13. Rijal B. Social distancing in the times of coronavirus pandemic. Anthrodendum. c2020. (Cited March 30, 2020). Available from: https://anthrodendum.org/2020/03/30/social-distancing-in-the -times-of-coronavirus-pandemic/

14. The United States Census Bureau. About Hispanic Origin; 2020. (Cited June 3, 2020). Available from: https://www.census.gov /topics/population/hispanic-origin/about.html

Manuscript received on 20 April 2020. Revised version accepted for publication on 10 June 2020

\section{Afrontamiento de la cuarentena y el distanciamiento social durante la pandemia por COVID-19 en los mayores de 60 años en los Estados Unidos}

RESUMEN Objetivos. Evaluar el impacto de la indicación de quedarse en casa y el distanciamiento social en los adultos de 60 años o más durante el brote de COVID-19 en los Estados Unidos en 2020.

Métodos. Utilizando un muestreo de conveniencia, se solicitó a los destinatarios que completaran una encuesta administrada por internet para explorar el impacto del distanciamiento social respecto de la soledad, el estrés y los cambios de comportamiento. La muestra analizada consistió en 833 respuestas de personas de 60 años o más.

Resultados. Una proporción importante de la muestra informó experimentar estrés (36\%) o soledad (42,5\%). En alrededor de un tercio de los casos se informó que la sensación de soledad aumentó durante el período de distanciamiento social. Los encuestados informaron que realizaban más actividades solitarias y menos actividades presenciales, utilizaban el correo electrónico y los mensajes de texto más de lo habitual y pasaban más tiempo que lo habitual con sus computadoras o tabletas. Aproximadamente dos tercios de las personas que respondieron informaron que utilizaban las redes sociales más que lo habitual. Se observaron diferencias significativa entre los encuestados más jóvenes (60-70 años) y los mayores (>71). Los cambios en la actividad física, el consumo de alcohol y de drogas recreativas y los cambios en los patrones de sueño también difirieron según la edad.

Conclusiones. El distanciamiento social tiene consecuencias significativas respecto de la soledad y los comportamientos que afectan a la salud en los adultos mayores de los Estados Unidos, muchas de los cuales varían según el grupo etario. Los resultados tienen implicaciones respecto de la indicación sostenida de quedarse en casa, así como para otros adultos mayores que deban estar confinados a su hogar por razones distintas a la pandemia.

Palabras clave Envejecimiento; infecciones por coronavirus; Estados Unidos. 